\begin{tabular}{|c|c|c|}
\hline $\begin{array}{l}\text { PKS } \\
\text { PULLIC } \\
\text { KNDWLEDGE } \\
\text { RROJECT }\end{array}$ & $\begin{array}{c}\text { REVISTA DE GEOGRAFIA } \\
\text { (RECIFE) } \\
\text { hitp://www.revista.upe.br/revistageografia }\end{array}$ & $\begin{array}{l}\text { OJS } \\
\text { OPEN } \\
\text { JOENAL } \\
\text { SYSTEMS }\end{array}$ \\
\hline
\end{tabular}

\title{
DESENVOLVIMENTO OU CRESCIMENTO ECONÔMICO? OS IMPACTOS DAS TRANSFORMAÇÕES RECENTES NO MUNICÍPIO DE GOIANA, PERNAMBUCO
}

\author{
Rodolfo Jorge Bezerra ${ }^{1}$; Anselmo César Vasconcelos Bezerra ${ }^{2}$ \\ ${ }^{1}$ Instituto Federal de Educação, Ciência e Tecnologia de Pernambuco. Email: rodolfojb@hotmail.com; \\ ${ }^{2}$ Instituto Federal de Educação, Ciência e Tecnologia de Pernambuco. Email: anselmo@ recife.ifpe.edu.br
}

Artigo recebido em 03/06/2017 e aceito em 23/01/2018

\section{RESUMO}

Nos últimos anos o município de Goiana no Estado de Pernambuco vem diversificando sua estrutura econômica, antes baseada na produção agrícola, para uma produção de base industrial, tendo como principais expoentes os polos industriais farmacoquímico, vidreiro e automotivo. Este artigo busca discutir como este município vem sendo impactado por esse processo de industrialização, bem como compreender como essa reorganização socioespacial está modificando a dinâmica de vida local. Para tanto foi realizada uma revisão de literatura sobre os conceitos de crescimento e desenvolvimento, assim como uma caracterização do município através de análise documental. Para a coleta de dados e informações primárias realizou-se entrevistas semiestruturadas com atoreschave, além de visitas de campo e de registros fotográficos. Observou-se que os empreendimentos industriais recém-chegados ao município vêm alterando a dinâmica econômica na região, e também gerando oportunidades para os moradores locais. Porém, devido à deficiência na capacitação profissional prévia dos moradores locais, as empresas que necessitam de mão de obra qualificada contratam funcionários oriundos de outras localidades. A chegada dessa nova parcela populacional impacta diretamente o setor imobiliário, a infraestrutura urbana e a prestação de serviços públicos do município. Os resultados apontam que o serviço de comércio foi o mais beneficiado com a chegada dos grandes empreendimentos, e que, por outro lado, a prestação dos serviços públicos, como segurança, mobilidade, saúde e saneamento básico sofreu um impacto negativo. Conclui-se que no atual momento, o município de Goiana não está inserido num processo de desenvolvimento includente e sustentável, ao contrário, o município parece caminhar no sentido de um desenvolvimento excludente baseado fortemente no crescimento econômico.

Palavras-chaves: Polo industrial, Desenvolvimento excludente, Goiana, Impactos socioambientais 


\title{
DEVELOPMENT OR ECONOMIC GROWTH? THE IMPACTS OF RECENT TRANSFORMATIONS IN GOIANA MUNICIPALITY, PERNAMBUCO
}

\begin{abstract}
In the last few years, Goiana municipality, in the State of Pernambuco, has diversified its economic structure, previously based on agricultural production, to an industrial production base, having as main exponents the industrial, pharmaco-chemical, glazing and automotive poles. This article aims to discuss how this municipality has been impacted by this process of industrialization, as well as to understand how this socio-spatial reorganization is modifying the local life dynamics. For data collection and primary information, semi-structured interviews were made with key actors, plus field visits and photographic records. It was observed that the industrial enterprises recently arrived at the municipality have been changing the economic dynamics in the region, and creating opportunities for the local residents. However, due to the lack of prior professional qualification of local residents, companies that require a skilled workforce hire employees from other locations. The arrival of this new population share impacts directly the real estate sector, urban infrastructure and the provision of public services in the municipality. The results indicate that the commercial service was the most benefited from the arrival of large enterprises and that, on the other hand, the provision of public services such as security, mobility, health and basic sanitation suffered a negative impact. It was concluded that at the moment Goiana municipality is not inserted in an inclusive and sustainable development process, on the contrary, the municipality seems to walk towards an excluding development strongly based in the economic growth.
\end{abstract}

Keywords: Industrial pole, Excluding development, Goiana, Socio-environmental impacts

\section{INTRODUÇÃO}

O Estado de Pernambuco tornou-se um dos principais centros industriais da região Nordeste, especialmente após a instalação do Complexo Industrial Portuário de Suape (CIPS), na Região Metropolitana do Recife (RMR), durante a década de 1970. Esse processo de industrialização intensificou-se no início século XXI, pois investimentos públicos e privados foram direcionados para obras de médio e grande porte, como, por exemplo, o Estaleiro Atlântico Sul, a Refinaria Abreu e Lima, a Companhia Petroquímica de Pernambuco (Petroquímica Suape), a Companhia Integrada Têxtil de Pernambuco e a Petrobrás Transporte (TRANSPETRO). Assim, o CIPS consolidou-se como um dos grandes polos industriais no Nordeste brasileiro.

Paralelamente a essa consolidação do CIPS e da industrialização na porção sul do território da RMR, houve uma desconcentração de investimentos privados, com importante suporte do poder público, para a área norte da RMR, especialmente nos municípios de Itapissuma e Igarassu, além do município de Goiana, que fica na Zona da Mata Norte, mas que possui um nível de integração bem consolidado com a metrópole recifense. No caso de 
Goiana, esse movimento de investimentos ancorados na indústria teve maior repercussão, uma vez que empreendimentos estratégicos e de grande impacto se instalaram no território.

O município de Goiana atualmente polariza uma região de desenvolvimento do Estado com muitos empreendimentos estruturadores (PERNAMBUCO, 2010). Dentre esses empreendimentos podemos citar a Empresa Brasileira de Hemoderivados e Biotecnologia (HEMOBRÁS) e a Vivix Vidros Planos, que injetaram na economia local cerca de um bilhão de reais na construção de suas plantas industriais (PERNAMBUCO, 2015). Outro grande e importante empreendimento a chegar a Goiana foi o polo automotivo, liderado pela fábrica da Jeep, indústria do grupo Fiat Chrysler Automobiles (FCA), que iniciou suas atividades em 2015, mas que já vinha modificando o cenário local desde 2012, quando se iniciaram as obras de construção.

Segundo informações de Pernambuco (2016), esses empreendimentos já impactam diretamente na economia do município, pois entre 2010 e 2013, o Produto Interno Bruto (PIB) municipal cresceu cerca de $70 \%$, indo de $\mathrm{R} \$ 894.270$ para $\mathrm{R} \$ 1.541 .134$. A participação da indústria nesse mesmo período cresceu 4,61\%, enquanto as participações da agropecuária e da prestação de serviços reduziram em $1,38 \%$ e 3,22\%, respectivamente. Tal crescimento se dá principalmente pelo tamanho do investimento feito pelos empreendimentos.

O polo automotivo, que possui uma área total de 1.100 hectares, teve um investimento inicial girando em torno de $\mathrm{R} \$ 7$ bilhões, dos quais $\mathrm{R} \$ 5$ bilhões foram alocados na fábrica da Jeep e os demais R $\$ 2$ bilhões nas indústrias que compõem o complexo. Atualmente, a fábrica está gerando 5.345 empregos, sendo 1.971 na planta, 2.524 no parque de fornecedores e 850 em empresas terceirizadas. Quando o polo estiver no seu limite produtivo, há a expectativa que 10 mil pessoas estejam trabalhando no polo (CLEMENTE, 2015).

É válido salientar que grande parte dos postos de trabalho não são preenchidos apenas por moradores de Goiana e municípios circunvizinhos, uma vez que existe uma demanda de mão de obra especializada não encontrada localmente. Assim, boa parte das vagas é preenchida por funcionários oriundos, principalmente, do Recife e de João Pessoa (PB), ambos equidistantes da fábrica. Além disso, ocupam cargos estratégicos no empreendimento, profissionais de outros estados e países.

Após a chegada desses grandes empreendimentos várias modificações socioespaciais têm acontecido na região, desde alterações no perfil da população residente e flutuante do município às mudanças de ordem socioambiental. Essa reorganização econômica e socioespacial têm impactando e poderá impactar ainda mais as condições de vida dos habitantes de Goiana, bem como irá demandar um maior esforço em políticas públicas Bezerra, Bezerra 2018 ISSN 0104-5490 
municipais, em setores como saúde, educação, habitação, segurança e saneamento.

Assim, o objetivo deste artigo será caracterizar e discutir o atual cenário do município identificando os principais impactos socioambientais resultantes desse processo de crescimento econômico acelerado e suas consequências na modificação das condições de vida da população local.

Os resultados apresentados podem fomentar a discussão sobre o crescimento de Goiana, uma vez que ainda existem poucos estudos desse caráter na região. Com base nas informações apresentadas será possível contribuir para análises atuais e futuras sobre a realidade socioespacial do município, além de se tratar de um estudo que pode auxiliar o desenvolvimento de políticas públicas que atendam e deem suporte às necessidades da população local.

A metodologia utilizada no artigo seguiu os procedimentos conforme com os objetivos da pesquisa. Para a identificação dos principais impactos socioambientais ocorridos pelo crescimento industrial foram coletados dados secundários em órgãos como o Instituto Brasileiro de Geografia e Estatística (IBGE) e a Agência Estadual de Planejamento e Pesquisas de Pernambuco (CONDEPE-FIDEM), além da revisão da literatura e de pesquisa documental. Foram realizadas entrevistas semiestruturadas com atores-chave ${ }^{1}$ como forma de produção de dados primários. Também foram realizadas visitas de campo a fim de identificar a dinâmica dos empreendimentos na região de estudo.

Para o diagnóstico dos atuais processos produtivos e inserção da população local nas atividades econômicas, foram coletados dados primários, através de visitas de campo, correlacionando com dados secundários provenientes de instituições competentes, tais como Serviço Nacional de Aprendizagem Industrial (SENAI), Agência de Desenvolvimento de Goiana (AD Goiana) e Agência do Trabalho. Também foram realizadas entrevistas semiestruturadas com atores-chave. Na discussão das entrevistas com os atores-chave, os nomes dos entrevistados foram suprimidos como forma de manter a integridade e sigilo do entrevistado.

O texto está estruturado em três partes. Na primeira realizou-se uma breve revisão sobre os conceitos de crescimento e desenvolvimento, sendo este último debatido a partir de diferentes vieses. Depois, caracterizou-se o município de Goiana e os principais aspectos referentes ao recente processo de industrialização local. Por fim, apresentam-se os resultados

\footnotetext{
${ }^{1}$ Ator-chave neste trabalho foi compreendido como representantes de instituições competentes do município, além de representantes da sociedade civil e dos setores econômicos locais.
} 
e discussão dividindo os tópicos por áreas: educação e empregabilidade, habitação, infraestrutura e comércio.

\section{CRESCIMENTO E DESENVOLVIMENTO: ENTRE A INCLUSÃO E A EXCLUSÃO}

A discussão sobre o conceito de desenvolvimento é bastante difundido no meio acadêmico, principalmente quanto se faz necessária à distinção entre desenvolvimento e crescimento econômico, pois muitos autores atribuem o crescimento constante nos níveis de renda como condição para se chegar ao desenvolvimento, sem que haja uma preocupação de como tais níveis de renda serão distribuídos. Deve-se acrescentar que "apesar das divergências existentes entre as concepções de desenvolvimento e crescimento, elas não são excludentes. Na verdade, em alguns pontos, elas se completam" (SCATOLIN, 1989, p.24).

O termo "desenvolvimento" começou a ser discutido com mais veemência durante o período pós-Segunda Guerra Mundial, quando o mundo esteve frente a frente com os problemas e desigualdades que assolavam o mundo, como a fome, miséria, desemprego, discriminação étnico-racial, problemas econômicos, sociais e ambientais.

Com a criação da Organização das Nações Unidas (ONU) em 1945, surgiu o primeiro documento oficial de grande importância que aborda as questões sobre desenvolvimento, que é a Carta das Nações Unidas, onde se abordavam os principais aspectos de promoção do desenvolvimento das nações, como o fim dos conflitos bélicos, a cooperação entre os países para a mitigação de problemas sociais, econômicos, cultural e humanitário (ONU, 1945).

Na obra Desenvolvimento como Liberdade, Amartya Sen (2010) procura analisar o desenvolvimento em contraposição ao viés econômico, que associa o desenvolvimento a fatores como crescimento do PIB, renda per capita, industrialização e avanço da tecnologia. Embora tais fatores contribuam diretamente para a melhoria da sociedade, o crescimento econômico não pode ser considerado um fim, e sim um meio para o desenvolvimento, que está relacionado com a melhoria da vida dos indivíduos e com suas liberdades.

Sen (2010) defende que o objetivo do desenvolvimento é proporcionar a "liberdade substantiva" dos indivíduos, ou seja, possibilitar que cada indivíduo possa decidir e escolher o que é melhor para si, como por exemplo, serviços de educação, saúde, liberdade política, liberdade religiosa, liberdade cultural, dentre outros. Uma vez que há falta de disposições sociais e econômicas, tais como os serviços de saúde e educação, essa liberdade substantiva 
deixa de existir, assim limitando a atuação dos cidadãos, condicionando-os a viver em vulnerabilidade social.

Esse tema possui uma roupagem atual, porém ele já era discutido desde a segunda metade do século XX, quando houve a publicação do relatório The Limits to Growth (Os Limites do Crescimento), em 1972, sobre a organização de Dornella H. Meadows. Nesse relatório, foi elaborado um modelo que apresenta cinco grandes preocupações de nível global: aceleração da industrialização; aumento dos indicadores de desnutrição; rápido crescimento populacional; deploração dos recursos naturais não renováveis; deterioração do meio ambiente.

Segundo Oliveira (2002) essas cinco preocupações servem como modelo em longo prazo, pensando na sobrevivência das gerações futuras e direcionando suas atenções para os problemas ambientais, como a poluição e a degradação do meio ambiente, que afeta significativamente a qualidade de vida da população, não somente em escala local, mas sim em escala global.

Paralelamente ao debate sobre crescimento e desenvolvimento surgem as primeiras discussões para melhorar a relação entre o homem e o meio ambiente. Em 1972, a Conferência das Nações Unidas sobre o Meio Ambiente Humano (CNUMAH), também conhecido como Conferência de Estocolmo, foi a primeira reunião organizada pela ONU para tratar das questões relacionadas à degradação ambiental e à busca pelo equilíbrio entre o crescimento econômico das nações e o impacto desse crescimento sobre o meio ambiente (LAYRARGUES, 1997).

No ano seguinte, Maurice Strong, que havia sido Secretário-Geral durante a CNUMAH, lançou o conceito de ecodesenvolvimento, que era adaptado aos países em desenvolvimento e diz respeito à proteção e manutenção dos recursos naturais, bem como à promoção de ações e medidas que visem alocar e utilizar tais recursos de forma consciente. Esse termo foi desenvolvido conceitualmente pelo economista Ignacy Sachs, que cria um modelo baseado nos pilares da eficiência econômica, justiça social e prudência ecológica com a finalidade de se obter o ecodesenvolvimento (LAYRARGUES, 1997).

Em 1992, durante a Conferência das Nações Unidas sobre Meio Ambiente e Desenvolvimento (CNUMAD), organizada pela Organização das Nações Unidas e realizada no Rio de Janeiro (ficando conhecida como Rio-92 ou Eco-92), foram discutidas as bases do desenvolvimento sustentável tendo como base a obra Our Common Future (Nosso futuro comum) de 1987, também conhecido como Relatório de Brundtland, em referência à coordenadora da Comissão Mundial sobre Meio Ambiente e Desenvolvimento (CMMAD), a 
norueguesa Gro Harlem Brundtland.

Esse relatório trazia a definição de desenvolvimento sustentável, que veio substituir o limitado conceito de ecodesenvolvimento, que não tinha uma dimensão global e apenas abrangia os países em desenvolvimento, como "o desenvolvimento capaz de suprir as necessidades da geração atual, sem comprometer a capacidade de atender as necessidades das futuras gerações" e trazia dentro dos seus objetivos um forte viés de proteção ao meio ambiente.

Essas considerações promovidas pela ONU e pelo Relatório Brundtland desmistificam as diferenças existentes entre os termos "desenvolvimento" e "crescimento". O desenvolvimento, em qualquer concepção, deve resultar do crescimento econômico acompanhado de melhoria na qualidade de vida, ou seja, deve incluir as alterações da composição do produto e a alocação de recursos pelos diferentes setores da economia, de forma a melhorar os indicadores de bem-estar econômico e social (pobreza, desemprego, desigualdade, condições de saúde, alimentação, educação e moradia) (VASCONCELLOS; GARCIA, 1998).

O desenvolvimento deve ser encarado como um processo complexo de mudanças e transformações de ordem econômica, política, social e ambiental. A abordagem da temática ambiental é mais um fator que corrobora para o esclarecimento da diferença entre crescimento e desenvolvimento. Apenas o aumento de produção de bens e/ou alocação de recursos financeiros não promove o desenvolvimento de uma região.

É notório que com a chegada de empreendimentos a uma região, o seu crescimento industrial acarretará um elevado crescimento econômico, porém, em contrapartida, poderá provocar uma modificação na dinâmica social e cultural da população. Por exemplo, o aumento da necessidade de serviços gerando assim uma maior demanda de políticas de saúde, educação, saneamento, entre outras.

De acordo com Sachs (2004) é de suma importância que haja o desenvolvimento includente em regiões que passam por um processo de (re)estruturação econômica tão significativa, como o caso do município de Goiana. É preciso que haja outros benefícios para a sociedade, além do econômico, tal como um melhor acesso aos serviços públicos.

A não reversão desse crescimento, em forma benéfica para a população local, pode acarretar no que chamamos de desenvolvimento excludente (SACHS, 2004). Para Cavalcanti (2013), esse desenvolvimento excludente acarreta um desastre para a população local, que sofre com os impactos negativos do crescimento da região. Todos os passivos gerados por esse crescimento impactam a população, como por exemplo, o déficit na prestação de serviços Bezerra, Bezerra $2018 \quad$ ISSN 0104-5490 
públicos, a não inserção da população local nos postos de trabalho, o aumento da violência, e ainda podemos incluir o uso de entorpecentes e a exploração sexual, dentre tantos outros problemas sociais.

Cavalcanti (2013) cita o exemplo ocorrido nas comunidades do entorno do Complexo de Suape, onde descreve a situação dos habitantes da região:

\footnotetext{
Não apenas pela destruição física de um ecossistema, mas também pela degradação humana, cultural e social. O que vi na região foi uma das coisas mais parecidas com o inferno que se pode imaginar na Terra. Não estamos percebendo a dimensão da tragédia. [...] O projeto tem sido caracterizado pela violência na retirada das famílias moradoras sem que indenizações justas sejam pagas, e nem novas moradias disponibilizadas, levando estes moradores a se tornarem sem teto, e famílias a viverem precariamente nas cidades localizadas em torno do complexo (CAVALCANTI, 2013).
}

Assim como Cavalcanti (2013), Perez e Gonçalves (2012) identificaram alguns problemas e conflitos socioambientais na região do CIPS ocasionados pelo crescimento acelerado, que não gerou uma inclusão social, muito menos um desenvolvimento includente. Lyra, Bezerra e Albuquerque (2015) ressaltam a importância de se pensar os polos de desenvolvimento, SUAPE e Goiana, como vetores de uma transformação socioespacial positiva, que gere crescimento econômico com inclusão social, mas observam que no caso de Goiana já se têm muitas semelhanças com o que aconteceu em SUAPE.

Outro problema iminente ocasionado pelo desenvolvimento excludente é a concentração de renda e riqueza. Um exemplo clássico dessa concentração de renda pode ser visto na contratação de funcionários que não sejam moradores locais. A necessidade de uma mão de obra especializada associada à falta de qualificação e capacitação dos habitantes locais faz com que as organizações busquem funcionários qualificados em outras regiões. Parte da renda desses funcionários oriundos de outros locais é transferida para família ou parentes.

Desta forma, a estrutura econômica dos polos geram bons lucros para as empresas do setor, porém boa parte desse lucro não é revertida para a população local.

Godoy (2013) explora esse problema de maneira simples, citando o que ocorre em Pernambuco, com relação ao Complexo Suape:

Hoje, o Produto Interno Bruto (PIB) per capita dos municípios de Ipojuca e Cabo de Santo Agostinho é o maior do estado (precisamente, dez vezes superior à média de Pernambuco), mas é notório o fato de que a renda média por lá é de apenas meio 
salário mínimo. Não é preciso ser um grande matemático ou economista para concluir que há, portanto, uma brutal concentração de renda e riqueza na região (GODOY, 2013).

Dessa forma, concordamos com Pereira (2005) no debate sobre o ônus de um crescimento econômico acelerado baseado num "desenvolvimento" planejado para curto prazo, a partir de estratégias que exploram pessoas e recursos naturais de forma inadequada, ecológica e socialmente, considerando essas dimensões como externalidades ao projeto central. Em Goiana, muitas dessas externalidades já são identificadas, como o incremento de veículos leves e pesados no trânsito, aumento no valor dos imóveis e custo de vida local, geração de resíduos sólidos e efluentes domésticos e industriais sem o devido tratamento, entre outros problemas que serão apresentados mais a frente.

\section{O MUNICÍPIO DE GOIANA}

Segundo IBGE (2010) o município de Goiana, localizado na Mata Norte de Pernambuco (Figura 1), possui uma área total de 445,814 km². Os limites municipais são ao norte com o Estado da Paraíba, ao sul com os municípios de Igarassu, Itaquitinga, Itamaracá e Itapissuma, a oeste com os municípios de Condado e Itambé, e a leste com o Oceano Atlântico. O bioma local predominante é a Mata Atlântica. 
Figura 1 - Localização do município de Goiana, Pernambuco.

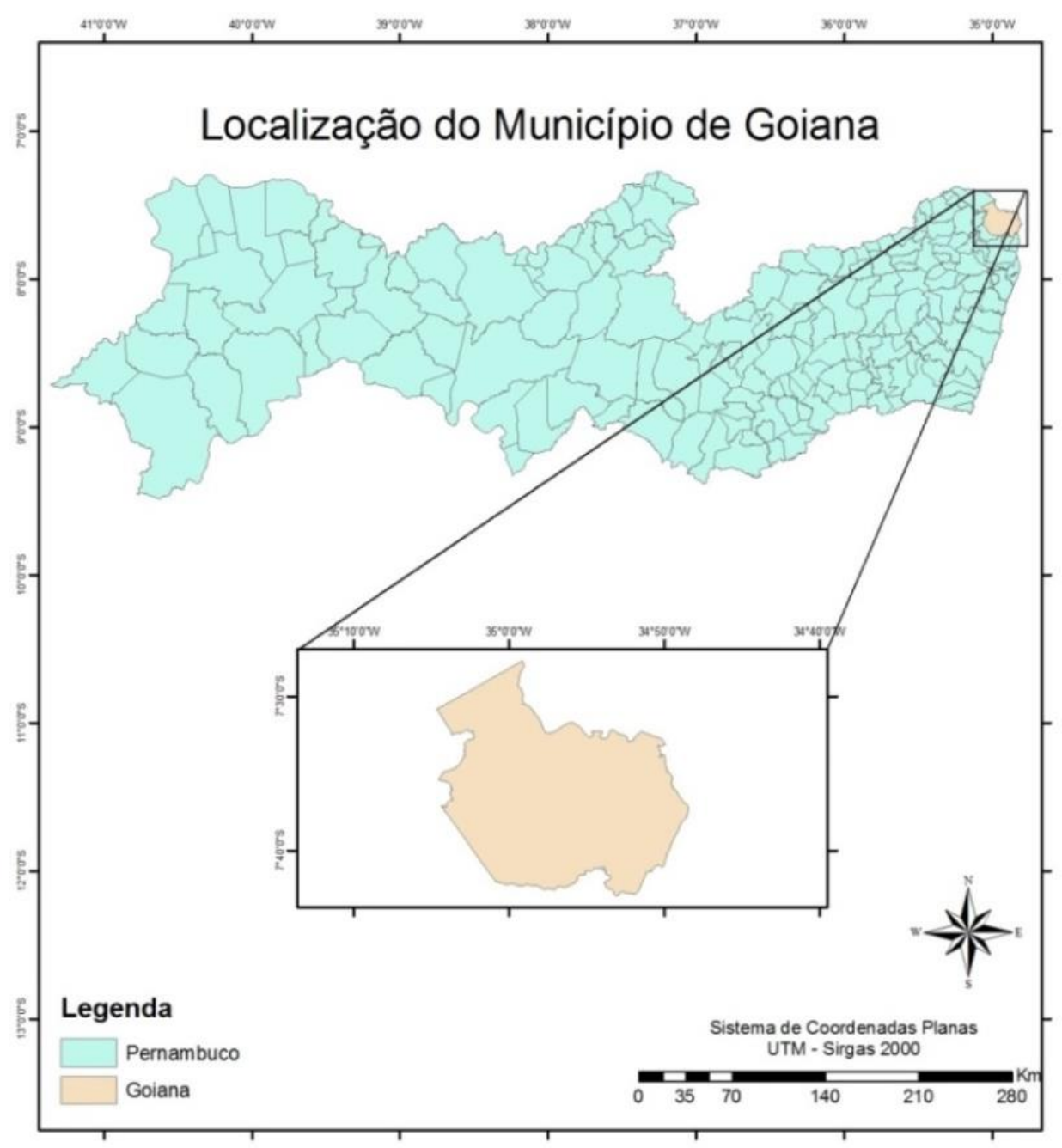

Fonte: Bezerra, 2015.

Administrativamente, o município é dividido em três distritos: Goiana, Ponta de Pedras e Tejucupapo. A população residente é de 75.664 habitantes, sendo 51,6\% de mulheres e 48,4\% de homens, conferindo assim uma densidade demográfica de aproximadamente 169 habitantes $/ \mathrm{Km}^{2}$. Desses habitantes, $76,7 \%$ reside na área urbana do município, ficando 23,3\% na zona rural. Aproximadamente $52 \%$ da população encontra-se na faixa etária entre 0 e 29 anos, 38\% entre 30 e 59 anos, e 10\% da população encontra-se acima dos 60 anos (IBGE, 2012).

Uma alta taxa de urbanização se caracterizou, principalmente entre 2000-2010, quando houve uma elevação de cerca de $20 \%$ na urbanização de Goiana, contrastando bastante, se comparado com as taxas de urbanização do estado de Pernambuco e do país (Gráfico 1). Esse crescimento na taxa de urbanização pode ser associado à mecanização do 
processo produtivo agrícola, acarretando em menos oportunidades de emprego nas áreas rurais, e, por consequência, o deslocamento dessa população para as áreas urbanas, além da nova dinâmica industrial que se inicia no município em meados da primeira década do século XXI.

Gráfico 1 - Comparativo da Taxa de Urbanização em Goiana, Pernambuco e no Brasil, 1970-

2010

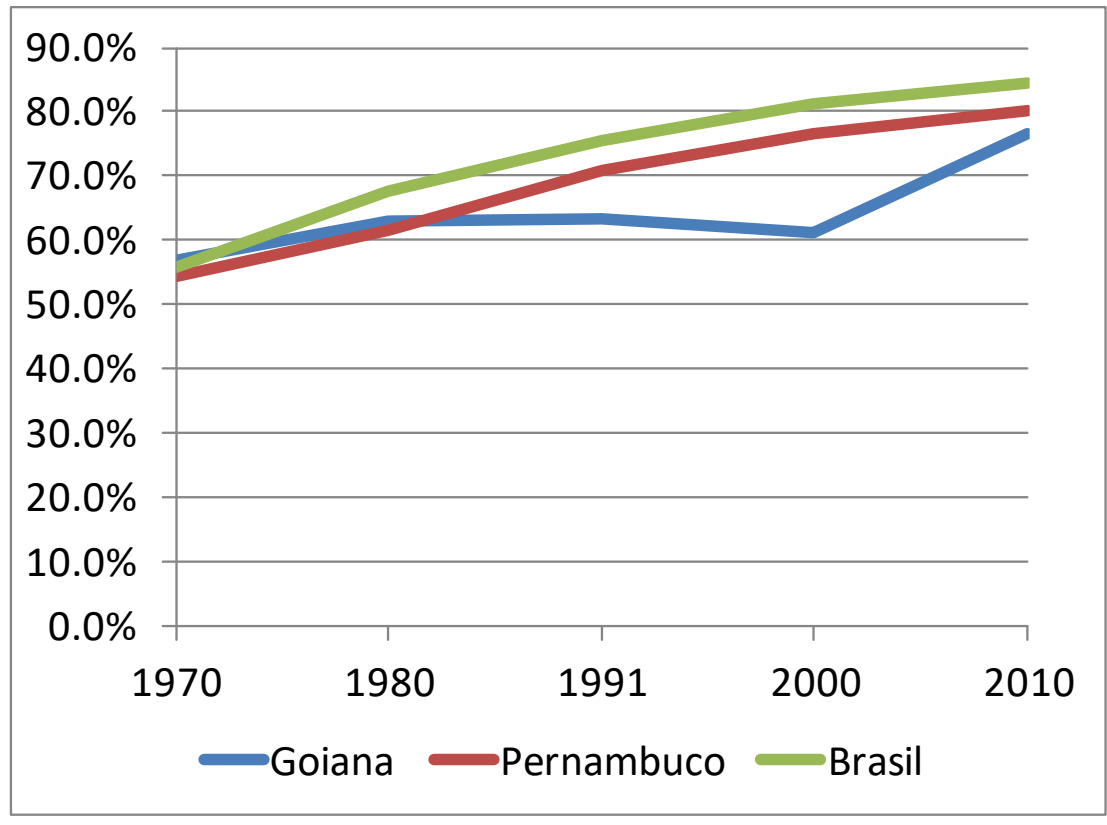

Fonte: IBGE - Censos Demográficos (1980, 1991, 2000 e 2010).

Mesmo com essa alta taxa de urbanização, Goiana ainda possui um forte poder econômico sustentado pela monocultura da cana-de-açúcar em boa parte da sua extensão territorial, gerando uma grande influência na região. Segundo dados da produção agrícola municipal de Goiana (2009), realizado pelo IBGE, mais de 90\% do valor financeiro da produção agrícola vem do cultivo da cana-de-açúcar. Essa produção agrícola corresponde a 5,1\% na participação do PIB do município (PERNAMBUCO, 2012).

O setor industrial do município, que agrega os segmentos de indústria de transformação, construção civil e extração mineral, é responsável por 35,02\% do PIB do município (PERNAMBUCO, 2012). Algumas indústrias já atuavam no município antes da chega dos grandes empreendimentos, como a papelaria Klabin e a fábrica de cimentos Nassau, porém em 2009, através da Lei Estadual no 950/2009 foi criado o Distrito Industrial de Goiana, que alavancou o fortalecimento desse setor com mais quatro indústrias (Produtos 
Pérola, Canaã, Goiana Pré-moldados e Concreto Redmix do Brasil). Essa lei facilitou a entrada para outras indústrias no município.

Segundo dados do IBGE, o ano de 2010 foi um divisor de águas no setor econômico do município. A chegada de novos empreendimentos industriais na região modificou radicalmente a ocupação setorial da população local. O setor que mais fechou postos de trabalho foi o agrícola, que em 2010 empregava 3.072 pessoas e em 2013 só havia 336 pessoas empregadas. No contraponto desse setor está o setor industrial, que em 2010 tinha 2.316 postos de trabalhos e com apenas três anos, praticamente triplicou seu contingente, com 6.141 empregados (Gráfico 2).

Gráfico 2 - Pessoas ocupadas por setor em Goiana 2007 - 2013

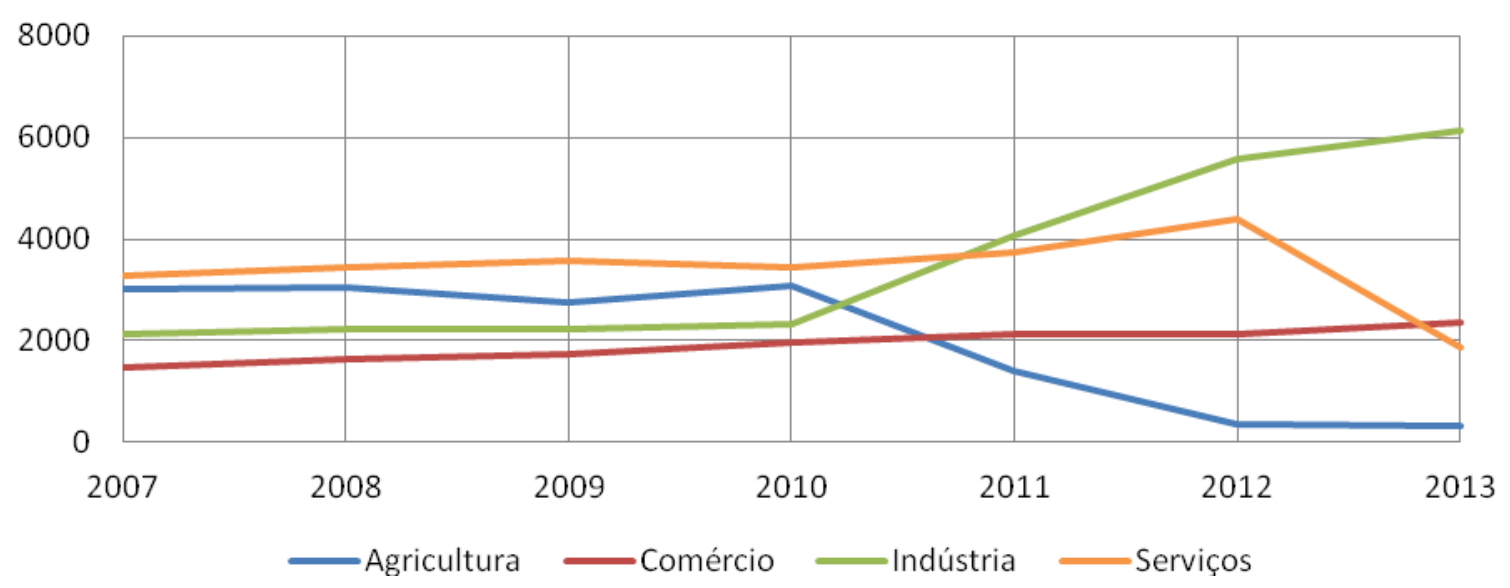

Fonte: IBGE, Cadastro Central de Empresas, 2014.

Completando a tríade econômica do município, o setor de comércio e serviços representou, em 2012, 59,88\% da receita bruta gerada por Goiana, aumentando em quase 5\% sua participação ao longo de 10 anos (PERNAMBUCO, 2012).

No ano de 2010, o município de Goiana apresentou um IDH de 0,651, ficando abaixo da média nacional e estadual, 0,727 e 0,673, respectivamente. Porém, houve uma significativa evolução se comparado aos dados de 2000, ano em que o município obteve 0,511 de índice. Esse crescimento de $27,4 \%$ se deve principalmente ao indicador de educação, que teve um acréscimo de 0,126 em relação ao ano de 2000, seguido da longevidade (aumento de 0,065) e renda (aumento de 0,064) (ATLAS BRASIL, 2013).

Quanto ao Índice de Gini, nas duas últimas décadas, o município manteve-se praticamente estagnado (0,55 em 1991, 0,56 em 2000 e 0,54 em 2010), porém abaixo da média nacional nesses 20 anos, que foi de 0,62. É esperado que, com a melhora nacional deste 
índice, os próximos relatórios do IBGE tragam números satisfatórios do município de Goiana (ATLAS BRASIL, 2013).

Segundo HEMOBRAS (2013), uma das maiores potencialidades do município é a presença expressiva de ecossistemas naturais que ocupam aproximadamente $25 \%$ do território e se dividem entre fragmentos de mata atlântica, manguezais, áreas pantanosas e mananciais de superfície. Por ser um município litorâneo, a existência e conservação dos manguezais é de suma importância para a sobrevivência e reprodução de espécies da fauna e da flora, bem como fonte de recursos para os moradores que dependem economicamente das atividades extrativistas.

Já Bezerra et al (2013) identificou a precariedade na questão da infraestrutura urbana, especialmente no que tange o saneamento e a habitação. A chegada dos grandes empreendimentos e os impactos resultantes dos mesmos ocorre paralelamente a um cenário de fragilidade no quesito infraestrutura no município. Um município com uma gama diversificada de empreendimentos estruturadores que ainda sofre, por exemplo, com a falta de água nas torneiras e uma deficiência grande na coleta e tratamento de esgotos domésticos.

\section{A DINÂMICA IMOBILIÁRIA}

O cenário da região de Goiana começa a se modificar na segunda metade da década de 2010, quando algumas grandes e estratégicas indústrias começaram a se estabelecer na região. Um dos primeiros polos industriais pensados para o município de Goiana foi o polo farmacoquímico, liderado pela HEMOBRÁS. Outro grande empreendimento estruturador é o polo vidreiro, liderado pela Vivix Vidros Planos que atua na produção de vidros incolores, coloridos, laminados e espelhos (PERNAMBUCO, 2015). Porém o maior empreendimento instalado no município de Goiana é o polo automotivo liderado pela Jeep, que junto com outras dezesseis empresas, comandarão o maior polo de produção de automóveis da região Nordeste (CESAR, 2014; PERNAMBUCO, 2015).

Alguns empreendimentos imobiliários foram planejados no município como forma de suprir a demanda por moradia e também elevar o valor do solo urbano. Um dos maiores investimentos nesse setor foi o Northville Empreendimento, que possui uma capacidade para abrigar 20 mil pessoas. A área total do empreendimento é de aproximadamente 50 hectares, com um investimento de $\mathrm{R} \$ 1$ bilhão, que viabilizarão a construção de lotes residenciais, apartamentos, prédios empresariais e de comércio (PEREIRA, 2013). Outro empreendimento 
do segmento imobiliário é liderado pelo grupo de investimentos Bom Negócio que aportou $\mathrm{R}$ \$ 7 milhões no Loteamento Novo Horizonte localizado ao lado do empreendimento Northville, na região noroeste do município. Esse empreendimento conta com 559 lotes e tem como foco os clientes com poder aquisitivo menor do que aqueles que adquiriram lotes no Northville. (PEREIRA, 2015a). O loteamento Vista Plena é outro que também aposta nas pessoas com menor poder aquisitivo para ser um empreendimento de sucesso. O loteamento possui lotes a partir de $240 \mathrm{~m}^{2}$ e tem como principal atrativo as condições de pagamento e baixos valores das mensalidades, com parcelas a partir de a partir de $\mathrm{R} \$ 235,00$ (VISTA PLENA, 2016).

Outro empreendimento que se instalaria no município é a Cidade Atlântica, que, pelo plano original, previa um investimento de R $\$ 3$ bilhões em uma área de 600 hectares com capacidade para 60 mil pessoas e 18 mil unidades habitacionais, sendo assim o maior bairro planejado de Goiana, porém devido a sua proximidade ao polo automotivo o empreendimento não vingou, com a justificativa de que essa proximidade poderia prejudicar o desenvolvimento e expansão do polo (PEREIRA, 2014). É importante destacar que esse padrão de condomínios fechados e cidades planejadas acompanha uma tendência nacional em cidades em expansão e com crescimento econômico positivo.

Após a identificação dos principais empreendimentos que aportaram no município de Goiana nos últimos anos, partiu-se para ouvir atores locais para melhor entender como essa nova dinâmica vem impactando, tanto de forma positiva como negativa na região e como o governo municipal e a população vêm se adaptando a essa nova realidade.

Abordando principalmente o setor imobiliário da região, um dos entrevistados foi um dos corretores imobiliário e representante de vendas do empreendimento Northville. Segundo o corretor, cerca de três mil pessoas vindas de Recife e João Pessoa foram contratadas pela Jeep durante a fase de construção do polo, criando uma demanda muito alta de casas para vender ou serem alugadas para acomodar tal contingente. Esse aumento de pessoas na região criou uma especulação imobiliária, principalmente em se tratando dos valores de aluguel, que chegaram a triplicar o seu valor quando a procura por residências se tornavam mais disputadas.

Segundo o entrevistado, essa procura por imóveis apenas esteve aquecida durante o período de construção do polo automotivo, e que agora, durante a fase de operação do polo, a procura por casas vem diminuindo gradativamente, inclusive com a devolução de imóveis alugados pela Jeep. Paralelamente, houve também, uma queda na venda dos lotes do empreendimento Northville. Ele ainda informou que a falta de infraestrutura básica oferecida Bezerra, Bezerra 2018 ISSN 0104-5490 
pelo município fez com que parte dos funcionários vindos de outros estados e que continuaram empregados no polo automotivo procurassem residência em municípios próximos, com melhor infraestrutura, como Recife e João Pessoa, corroborando com o debate trazido por Bezerra et al (2013) e HEMOBRÁS (2013).

Sobre o Northville, o entrevistado informou que o empreendimento possui 105 lotes, onde já estão vendidos $50 \%$ do condomínio fechado. Desses lotes já vendidos, ele informa que a maior parte destes lotes foi vendido para moradores de Goiana, já estabilizados financeiramente, que procuram melhores condições de vida, e uma pequena parcela de italianos e portugueses que vieram para trabalhar no polo automotivo.

Quando questionado sobre o público que adquiriu lotes no empreendimento Northville, o entrevistado respondeu:

O público do Northville é o "público A", enquanto o Novo Horizonte é "C". Para você ter uma ideia, aqui a entrada do lote é de $\mathrm{R} \$ 31$ mil e lá é de $\mathrm{R} \$ 5$ mil. Aqui o valor total do lote é de $\mathrm{R} \$ 160$ mil até $\mathrm{R} \$ 320$ mil e no Novo Horizonte é de $\mathrm{R} \$ 78$ mil. (Entrevista em 03/06/2015).

A fala do entrevistado deixa claro que houve uma estratégia mercadológica por parte dos empreendimentos imobiliários em criar possibilidades para os vários públicos dispostos a adquirir um imóvel com infraestrutura diferenciada e com preço e condições acessíveis. Entretanto a realidade do município já evidencia alguns processos de crescimento urbano em áreas sem infraestrutura, com moradias construídas com materiais inadequados, como taipa e madeira, e localizadas em áreas de risco, como margens de rios e pequenas encostas. Conforme HEMOBRÁS (2013) existem áreas periféricas em alguns bairros com infraestrutura precária e problemas de ordem social, como tráfico de drogas e violência urbana.

A precária infraestrutura básica do município e sua proximidade com a RMR e o município de João Pessoa, na Paraíba, criou certa apreensão por parte do setor imobiliário, uma vez que nesses municípios próximos há uma melhor prestação de serviços e condições de infraestrutura, possibilitando assim que os funcionários oriundos de outras regiões prefiram se deslocar para essas áreas diariamente ao invés de fixar moradia em Goiana, o que pode inviabilizar os empreendimentos imobiliários na região.

Desta forma era necessário ofertar habitações com prestação de serviços e infraestrutura equivalentes, que foram supridas pelos empreendimentos habitacionais focados Bezerra, Bezerra 2018 ISSN 0104-5490 
em loteamentos e condomínios fechados. Entretanto se faz necessário ter um olhar diferente para a população com menor poder aquisitivo, para que ela não seja socialmente excluída desse processo de expansão urbana no município.

Um dado importante e que deve ser ressaltado no que diz respeito à relação entre o poder público e as empresas, é a regularização do empreendimento Northville perante a legislação vigente. O Plano Diretor de Desenvolvimento Urbano de Goiana (2004) define um percentual de 5\% da área do imóvel destinada à constituição do Banco de Terras Municipal (BTM). Deste modo, o empreendimento destinou 5\% do total da sua área para o município, onde estão sendo construídas uma Unidade Pernambucana de Atenção Especializada (UPAE) e uma Unidade de Pronto Atendimento 24h (UPA 24h), além do Tribunal Regional do Trabalho.

Além do terreno destinado pelo empreendimento Northville, a construção da UPAE possui, como contrapartida, investimento da Fiat Chrysler Automobiles (FCA), que está financiando a construção da unidade de saúde, que será operacionalizada pelo Governo do Estado de Pernambuco. Com o investimento de R 14 milhões, a UPAE terá o potencial de atendimento de 140 mil consultas, 350 mil exames e 6.780 cirurgias por ano, esperando beneficiar os moradores da Zona da Mata Norte do Estado, que, em sua maioria, dependem do Sistema Único de Saúde (SUS) (PEREIRA, 2015b).

\section{EDUCAÇÃO E EMPREGABILIDADE}

O município de Goiana tinha como principal força econômica a produção da canade-açúcar, que predominou no município por séculos.

Com a crise no setor sucroalcooleiro em 2008, ocasionada principalmente por fatores climáticos, o município precisou encontrar meios que pudessem suprir esse déficit financeiro, abrindo suas portas para a captação de novos investimentos. A chegada dos polos farmacoquímicos, vidreiro e automotivo foram o suspiro do município perante a estagnação econômica que a região vivia (Informação verbal através de entrevista em 03/06/2015).

Segundo o representante da AD Goiana, a chegada desses empreendimentos trouxe um receio para o poder municipal devido à falta de infraestrutura local. Era de suma importância trazer investimentos para Goiana no setor de saúde, educação e saneamento 
básico. A prioridade do município ficou em inserir a população local e do seu entorno nas vagas de emprego que seriam disponibilizadas, principalmente pela Jeep, por isso os investimentos em educação foram debatidos em primeira instância.

Esse investimento em educação não traz somente benefícios para a questão de empregabilidade e inserção da população local nos postos de trabalho, mas sim na possibilidade de tornar os cidadãos em formadores de opinião conscientes, tendo bases para argumentar e questionar os representantes locais, cobrando aquilo que se tem de direito e participando ativamente nas decisões importantes do município. Essa participação da sociedade faz jus ao conceito de desenvolvimento abordado por Sen (2010), que visa à liberdade de escolha das pessoas, tal como a luta pelos seus direitos.

Dados do censo escolar do IBGE (2011) mostram que não houve um investimento maior por parte das esferas administrativas no que tange à educação profissional antes da chegada dos empreendimentos estruturadores e que apenas 2,6\% das matrículas naquele ano foram voltadas para essa modalidade, inviabilizando a inserção da população local nas atividades industriais que requerem um conhecimento especializado.

Para que essa situação fosse mitigada, foi necessária uma rápida intervenção por parte do poder municipal, a fim de capacitar a população local e preencher as oportunidades que ali surgiam. Desta forma, o poder municipal junto com o SENAI firmou uma parceria com a FCA para qualificar profissionais no ano de 2014. Qualificou, inicialmente, cerca de 3.200 profissionais para trabalhar na construção do polo, e agora prepara a inauguração de três unidades voltadas para o setor automotivo: uma faculdade, uma escola e um instituto de tecnologia automotiva (GUARDA, 2015).

A Escola SENAI em Goiana tem investimentos de $\mathrm{R} \$ 13,3$ milhões, com funcionamento iniciado no segundo semestre de 2016, oferecendo os cursos de eletrotécnica, eletromecânica, automação industrial e costura industrial. A Faculdade de Tecnologia SENAI em Engenharia Automotiva, que já disponibiliza os cursos superiores em Tecnólogo em Mecatrônica Industrial e Análise e Desenvolvimento de Sistemas, terá um investimento de R\$ 49 milhões para iniciar o Bacharelado em Engenharia Automotiva. Já o Instituto SENAI de Tecnologia Automotiva irá prestar serviços de consultoria, ensaios laboratoriais e assessoria técnica para a FCA e os fornecedores da cadeia automotiva. Com o investimento de R\$15 milhões, a unidade ficará localizada no município de Igarassu e tem previsão para iniciar os trabalhos no primeiro semestre de 2017 (GUARDA, 2015).

Ainda abordando os temas de postos de trabalho e investimento em capacitação profissional da população local, um dos atores entrevistados foi a representante da Agência do Bezerra, Bezerra 2018 ISSN 0104-5490 
Trabalho de Goiana. Ela informa que, desde a chegada da Jeep, junto com o polo automotivo, foram empregados cerca de 2 mil moradores de Goiana e que, atualmente, $70 \%$ desse contingente continua empregado no polo e os demais $30 \%$ estão procurando recolocação profissional no momento.

Em relação à capacitação profissional, o entrevistado afirmou:

Houve um crescimento significativo nas oportunidades de emprego no município, além de capacitações promovidas, principalmente, pelas empresas do polo automotivo, porém não houve uma dedicação por parte da população, como o curso de automação oferecido para 40 pessoas e que só 12 se formaram e estão trabalhando no polo (Informação verbal através de entrevista em 30/03/2015).

A informação do representante da Agência de Trabalho em relação à capacitação profissional no município reafirmam os dados trazidos pelo Censo Escolar de 2011 do IBGE, no qual se comprova que não houve investimento prévio em educação profissional e que a maior parte dessa capacitação da população local é proveniente de ações das indústrias do polo automotivo, e mesmo com a intervenção do poder público e privado, há certa dificuldade em capacitar profissionalmente à população goianense.

Um dado expressivo fica por conta do contingente de cidadãos goianenses que estão trabalhando nos postos de trabalho criados pelo polo automotivo. Dos 9.000 postos de trabalhos criados pelo polo, apenas 1.400 postos estão sendo preenchidos pela população local, o que representa um valor aproximado de $15 \%$ do total de vagas. Esse baixo valor é reflexo da necessidade do polo em ter funcionários qualificados, mas que não os encontram no município devido à falta de um trabalho prévio na capacitação da população, que apenas começa a se qualificar após o início das atividades operacionais do polo. O diagnóstico socioambiental realizado pela HEMOBRÁS (2013) já demonstrava uma preocupação em não ter a população local absorvida pelos novos postos de trabalho devido ao déficit de investimentos no setor educacional do município. Essas informações dão indícios que, se não houver uma maior preocupação com os programas e ações de capacitação profissional, a população local sofrerá com a falta de oportunidades, conforme Sen (2010) correndo o risco de serem excluídos do processo de desenvolvimento do município. 


\section{COMÉRCIO E INFRAESTRUTURA}

O município de Goiana sempre teve um comércio expressivo, uma vez que o município é polo de uma RD do estado de Pernambuco, inclusive com influência sobre municípios paraibanos. Em relação aos impactos dos megaempreendimentos frente ao comércio local, o representante da AD Goiana afirma que três setores foram diretamente impactados: os prestadores de serviços alimentícios - como bares, restaurantes, lanchonetes e supermercados -, as clínicas particulares de exames admissionais, visto que o fluxo de contratações era constante e necessitava uma atenção, e o setor de hospedagem, como pousadas e albergues.

Essa afirmação corrobora com as informações colhidas através da entrevista realizada com um comerciante local. Morador de Goiana há 45 anos e comerciante há 20 anos, ele informa que com a chegada desses novos empreendimentos, principalmente do polo automotivo, houve sim um crescimento em relação ao comércio, principalmente no setor alimentício, com um número crescente de restaurantes que abriram na região para suprir a demanda das empresas, que chegam a fechar contratos para garantir a alimentação da força de trabalho.

É notório que, com o adensamento populacional em uma região, a demanda pela prestação de serviços aumenta e o comércio é um dos setores mais impactados com esse crescimento. $\mathrm{O}$ setor de alimentos é o principal beneficiado com esse acréscimo populacional e econômico na região por se tratar de uma necessidade básica universal. Outros setores varejistas também absorvem parte desse impacto na região, como o setor de vestuário, farmácias, eletroeletrônicos e materiais de construção. Essas informações são corroboradas pelos dados da PERNAMBUCO (2012), que mostram a participação do setor de comércio e serviços em aproximadamente $60 \%$ da receita bruta gerada no município de Goiana. Esse crescimento no setor comercial gera renda e emprego, desenvolve o município e promove o fortalecimento dos demais setores econômicos da região.

Além do aspecto comercial, o entrevistado aborda outras questões, como a prestação de serviço de saúde, saneamento e segurança:

O município se mantém com a mesma infraestrutura de antes da chegada dos empreendimentos. Só há um hospital para o atendimento público e um hospital particular, que não suprem a necessidade local. Não há saneamento básico completo, apenas a distribuição de água encanada e não há rede de esgoto. A insegurança vem 
aumentando bastante, com assaltos e furtos durante todo o dia. Houve um crescimento na violência (Informação verbal através de entrevista em 03/06/2015).

As informações reveladas pelo comerciante local, sobre questões de infraestrutura no abastecimento de água e rede de coleta de esgoto, reafirmam os dados obtidos no IBGE (2010), HEMOBRÁS (2013) e Bezerra et al (2013).

Em relação à distribuição de água, a média municipal de casas ligadas à rede pública de abastecimento de água é de $65,52 \%$, porém há uma disparidade desse valor quando analisamos a área central do município, que possui quase $95 \%$ de casas atendidas por esse abastecimento, em relação a áreas rurais, como por exemplo, o Assentamento Rural de Ubu, que não possui nenhuma casa atendida pela rede de distribuição de água, mostrando a deficiência na prestação deste serviço por parte do município (Bezerra et al, 2013).

Esses dados são significativos, uma vez que a água é um recurso básico à vida e prérequisito para o desenvolvimento humano. A falta ao acesso à água é vista como parâmetro de associação das condições de vida à pobreza, desigualdade sociopolítica e econômica, estabelecendo assim uma vulnerabilidade social. Não há como se falar em desenvolvimento quando o recurso mais importante à vida não é acessível a todos.

Em relação ao esgotamento sanitário, percebeu-se claramente a precariedade da prestação desse serviço no município. A rede de coleta máxima de esgoto atinge o valor de $51 \%$ na área central do município, entretanto não há tratamento dos efluentes coletados e que são oriundos não somente de residências, mas como de áreas de práticas agrícolas, com o uso de agrotóxicos, que contaminam o solo, o subsolo, os aquíferos subterrâneos e os cursos de água da região (HEMOBRÁS, 2013).

Esses dados mostram a deficiência do poder público em universalizar a prestação de serviços essenciais para o desenvolvimento do município, e que, na sua ausência, pode agravar os níveis de enfermidades na região, gerando um quadro negativo ao setor de saúde pública, que também se encontra em déficit no município (Bezerra et al, 2015).

Como afirma Sen (2010), o desenvolvimento deve estar relacionado à melhoria de vida dos indivíduos tal como as suas liberdades, possibilitando que cada pessoa possa escolher o que é melhor pra si, e a limitação da prestação de serviços essenciais, como acesso a água e saneamento, impede a atuação do indivíduo frente à sociedade. Tal limitação também é descrita por Sachs (2004) como a exclusão de uma parcela social no desenvolvimento neste caso, crescimento, pois a população se depara de forma mais expressiva com os 
passivos ocasionados pelo boom industrial - da região, que fica a mercê das ações do poder público.

A deficiência na prestação de serviços públicos e defasagem da infraestrutura urbana não podem ser vistas como uma simples consequência do processo de crescimento econômico da região. Este passivo social deve ser encarado como objetivo a ser mitigado pelo poder público, através de ações e articulações com o governo federal, estadual e com iniciativas privadas.

$\mathrm{O}$ representante da $\mathrm{AD}$ Goiana cita que, devido ao aumento do volume de pessoas que estariam morando e circulando pelo município, eram necessários investimentos nos setores de habitação, saúde e saneamento básico, uma vez que os mesmos se encontravam em precárias condições e necessitavam de uma atenção especial. Assim, através de parcerias e intervenções do poder estadual, o município conseguiu se articular, trazendo investimentos nos setores de saneamento, saúde e urbanização.

Atualmente o principal investimento no setor de infraestrutura no município de Goiana se dá através da Parceria Público-Privada (PPP) entre o governo de Pernambuco, com a Companhia Pernambucana de Saneamento (COMPESA) e o consórcio formado pelas empresas Foz do Brasil, do Grupo Odebrecht, e Lidermac Construções. Essa PPP trará investimentos de R \$ 4,5 bilhões em saneamento básico e tem como objetivo elevar os índices de atendimento do serviço de saneamento básico nos 14 municípios da RMR e no município de Goiana. É esperado que, num intervalo de 12 anos, cerca de 3,7 milhões de pessoas sejam beneficiadas com essa parceria (CAMAROTTO, 2013).

Ainda sobre os investimentos em infraestrutura, dados do Ministério do Planejamento (2016) informam que no município de Goiana estão sendo realizadas quinze obras de infraestrutura social e urbana beneficiadas pelo Programa de Aceleração do Crescimento (PAC). Destas quinze obras podemos destacar sete empreendimentos no setor de saúde (construção da Unidade de Pronto Atendimento - UPA - e melhoria em seis Unidades Básicas de Saúde - UBS), três empreendimentos no setor de saneamento (ampliação do sistema de abastecimento de água do distrito de Tejucupapo e Ponta de Pedras, ampliação e melhoria do sistema de esgotamento sanitário da RMR e do munícipio de Goiana e a implantação do sistema adutor de água para o Polo Farmacoquímico de Goiana) e um investimento no setor de Urbanização de Assentamentos Precários, com a urbanização da comunidade Caixa d'Água. 
Com exceção da obra de Ampliação e Melhoria do Sistema de Esgotamento Sanitário, por não ser um investimento exclusivo no município de Goiana, essas obras terão cifras que se aproximam de $\mathrm{R} \$ 27$ milhões, conforme o quadro abaixo:

Quadro 1 - Investimentos em infraestrutura no município de Goiana/PE

\begin{tabular}{|c|c|}
\hline Setor & Investimento \\
\hline Saúde & $\mathrm{R} \$ 2.298 .400,00$ \\
\hline Centros e Quadras & $\mathrm{R} \$ 6.350 .392,82$ \\
\hline Creche & $\mathrm{R} \$ 1.273 .219,89$ \\
\hline Saneamento & $\mathrm{R} \$ 12.457 .329,24$ \\
\hline Urbanização & $\mathrm{R} \$ 4.501 .271,38$ \\
\hline Total & $\mathrm{R} \$ 26.880 .613,33$ \\
\hline
\end{tabular}

Fonte: Ministério do Planejamento - PAC, 2016.

Esses problemas de falta de infraestrutura e déficit na prestação de serviços públicos são históricos no município, principalmente para as moradias localizadas nas áreas rurais e em ocupações irregulares, na periferia do centro urbano. A falta de investimentos no tocante a abastecimento de água e esgotamento sanitário mostra o déficit de atenção por parte do poder público no que diz respeito às condições básicas de saúde dos menos afortunados. Fica evidente que há desigualdades socioespaciais no município, que os investimentos para diminuir essas diferenças ainda são pontuais.

Mesmo com as intervenções do poder público frente às necessidades da população local, como, por exemplo, a capacitação e profissionalização dos moradores, a PPP para melhorar as condições sanitárias do município e as demais obras de infraestrutura beneficiadas pelo PAC, elas chegam com certo atraso na região, uma vez que elas deveriam ser elaboradas e executadas antes da chegada dos empreendimentos, e não após, como medida mitigadora.

Não houve um planejamento estruturador para a chegada destes novos empreendimentos de grande porte, nem de uma nova parcela de habitantes na região, o que preocupa significativamente a prestação dos principais serviços públicos, como abastecimento de água e coleta de efluentes, capacitação profissional e prestação de saúde pública, e a tendência, caso não mude essa realidade com as intervenções municipais, é que tais serviços 
se tornem cada vez mais precários, deixando de atender parcelas populacionais que ainda se beneficiam desses serviços.

\section{CONCLUSÕES}

Este artigo se propôs a realizar uma caracterização do atual cenário do município de Goiana de forma que fosse possível compreender quais seriam os impactos, positivos e negativos, da chegada de grandes empreendimentos estruturadores na região, e o que modificaria em relação à situação econômica, social, espacial e ambiental do município.

Esse novo cenário industrial começa atraindo habitantes para o centro urbano, na expectativa de conseguir uma das oportunidades que ali surgem. Porém, para a inserção da população no setor industrial, é necessário que haja uma capacitação profissional prévia para que não ocorra o desenvolvimento excludente, verificado atualmente em Goiana.

Essa capacitação profissional da população goianense tardou a acontecer e sem um trabalho prévio de profissionalização da população antes da chegada de tais empreendimentos dificultou a inserção da população local nos postos de trabalho que ali surgiam, fazendo com que essa parcela dos postos de trabalho fosse preenchida com mão de obra oriunda de outros lugares. Devido a essa nova parcela populacional que se aglomera no centro urbano, a prestação de serviços públicos e a infraestrutura urbana, que já se encontrava deficitária, começam a se deteriorar mais, demandando um investimento urgente para que os principais serviços públicos, tais como, saúde, educação, segurança e saneamento, voltem a atender a parcela que era beneficiada por esses serviços e expandam a capacidade de ação para a população que está crescendo.

Com a responsabilidade de mitigar esses problemas, o governo municipal começou a se articular com outras esferas governamentais, instituições e com as próprias empresas que ali se firmavam, realizando uma série de investimentos na capacitação e profissionalização dos moradores de Goiana e do seu entorno. Esses investimentos pontuais em capacitação profissional revelam um déficit no planejamento educacional do município e que merece uma atenção especial, pois a educação é um dos principais vetores de mudança e inclusão social, não somente nas atividades econômicas do município, mas também nas relações sociais e políticas.

No tocante ao saneamento básico, o município foi contemplado graças a uma PPP entre o Governo Estadual e o Consórcio Foz do Brasil, que se responsabilizará em melhorar a 
infraestrutura sanitária do município até 2025. Entretanto, até o momento desta pesquisa, as obras estavam num ritmo bastante lento, levando a crer que essa meta temporal não será cumprida. Demais obras de urbanização, melhoria de creches e de unidades básicas de saúde terão investimento do governo federal, através do Programa de Aceleração do Crescimento. É de suma importância que o poder municipal possa tomar a frente em investimentos em saneamento básico e infraestrutura, mesmo com a participação de outras esferas governamentais, e que parte dos recursos financeiros advindos dessa expansão industrial na região seja alocado nessas melhorias, que contribuem enormemente para o bem estar da população e desenvolvimento do município.

No tocante à habitação, verificou-se uma forte especulação imobiliária, alavancando o preço de casas, terrenos e aluguéis de imóveis, apenas diminuindo quando parte dos trabalhadores do canteiro de obras do polo automotivo deixou o município, tornando os empreendimentos imobiliários como uma opção de escape. Porém, mesmo com uma gama de empreendimentos imobiliários na região, a temática habitacional é um dos principais problemas a ser encarado pelo poder público e deve-se cumprir a sua responsabilidade de ofertar moradia para a população, não ficando apenas à mercê dos empreendimentos privados, mas que o município possa desenvolver acordos e parcerias no setor habitacional, utilizandose de programas governamentais já existentes, como o programa social Minha Casa, Minha Vida.

Outro problema a ser mitigado pelo poder público se refere às condições ambientais do município, que vem se deteriorando ao longo do tempo, e com a chegada dos empreendimentos estruturadores e a nova parcela populacional, tende a se agravar. $\mathrm{O}$ principal problema ambiental é a precária rede de abastecimento de água no município, além disso, o esgoto sem tratamento que polui os rios e cursos d'água locais, mais a disposição irregular de resíduos sólidos e a falta de coleta e limpeza periódica são questões que exigem uma mudança radical do ponto de vista das políticas públicas municipais. O acúmulo de resíduos sólidos no município acarreta a proliferação de animais peçonhentos e vetores de enfermidades, impactando diretamente nas condições de saúde e sanitárias da região. Além disso, o acúmulo desse material em galerias, vias públicas e afluentes, associadas às épocas de chuva, podem influenciar diretamente em alagamentos e enchentes. Ademais, outras questões ambientais devem ser observadas e controladas, antes que tomem maiores proporções, como a poluição sonora, a poluição atmosférica e a contaminação de fontes e reservatórios de água.

Em contraponto a esses efeitos negativos, podemos afirmar que houve um crescimento vertiginoso de arrecadação no comércio local e na prestação de serviços. O setor Bezerra, Bezerra 2018 ISSN 0104-5490 
alimentício, como restaurantes, bares, lanchonetes e supermercados, foi o principal setor beneficiado com a chegada desses empreendimentos à região devido à necessidade básica de alimentação por parte dessa nova parcela populacional que chega ao município. Porém, este não é o único setor beneficiado. O setor hoteleiro e as clínicas particulares que oferecem exames de admissão também sentiram os efeitos positivos da chegada desses polos industriais, tais como os setores de vestuário, farmácia, materiais de construção e de eletroeletrônicos.

É importante salientar que, mesmo com os esforços do poder público em mitigar as consequências negativas desse crescimento industrial, as suas ações tardaram a acontecer, causando problemas sociais na região. Era de suma importância que esses investimentos, que agora cercam o município, estivessem acontecendo antes da chegada desses empreendimentos, possibilitando assim uma maior inserção da população local nos postos de trabalho e menos déficits na prestação de serviços urbanos, assim gerando mais renda para a população e melhores condições de vida.

Dessa forma, o atual cenário do município de Goiana não foge à regra das pequenas e médias cidades que abrigam polos industriais. Se por um lado, as receitas crescem para a prefeitura e a economia local se aquece com a circulação de dinheiro, por outro, os problemas históricos que nunca foram resolvidos se acentuam. Definitivamente, o crescimento econômico que impacta a região de Goiana não está se traduzindo em desenvolvimento com inclusão social, ao contrário, o legado recente da instalação desse novo "polo de desenvolvimento" no Estado de Pernambuco tem deixado marcas, como o aumento da violência, diferentes formas de poluição, frustração pela baixa empregabilidade, e da reprodução das desigualdades sociais num município que conviveu quinhentos anos com a monocultura da cana-de-açúcar como principal atividade econômica.

\section{REFERÊNCIAS}

BEZERRA, A. C. V. et al. Condições sanitárias no município de Goiana-PE: construindo um diagnóstico com a participação das comunidades. Divulgação em Saúde para Debate, Rio de Janeiro, v. 50, p. 48-56, 2013.

BEZERRA, A. C. V. et al. Diagnóstico participativo do setor saúde no município de Goiana, Pernambuco. Espaço \& Geografia, Vol.18, No 2, 347:366, 2015. 
BRASIL. Instituto Brasileiro de Geografia e Estatística (IBGE) - Goiana / PE. Disponível em: http://ibge.gov.br/cidadesat/painel/painel.php?codmun=260620. Acessado em $17 / 06 / 2014$.

Atlas do Desenvolvimento Humano no Brasil, 2013. Disponível em: http://www.atlasbrasil.org.br/2013/pt/perfil_m/goiana_pe. Acessado em 11/10/2016. Ministério do Planejamento. Programa de Aceleração do Crescimento. Disponível em: http://www.pac.gov.br/infraestrutura-social-e-urbana. Acessado em 09/10/2016. CAMAROTTO, Murillo. Pernambuco assina PPP de $\mathbf{R} \mathbf{4 , 5}$ bi para saneamento. Valor Econômico, Caderno $\quad$ Brasil, $2013 . \quad$ Disponível em: http://www.valor.com.br/brasil/3008508/pernambuco-assina-ppp-de-r-45-bi-para-saneamento. Acessado em 01/10/2016.

CAVAlCANTI, Clóvis de Vasconcelos. O Projeto de Suape e suas relações econômicas e socioambientais. $65^{\mathrm{a}}$ Reunião Anual da Sociedade Brasileira para o Progresso da Ciência SBPC, Recife, 2013.

CESAR, Julio. Fiat Chrysler anuncia nomes de parceiros para a nova fábrica em Goiana (PE). Carplace, 2014. Disponível em http://carplace.uol.com.br/fiat-chrysler-anuncia-nomesde-parceiros-para-a-nova-fabrica-em-goiana-pe/. Acessado em 02/12/2014.

CLEMENTE, André. Fábrica da Jeep em Goiana dá a largada oficial no mercado automotivo brasileiro. Diário de Pernambuco, Caderno Economia, 2015. Disponível em http://www.diariodepernambuco.com.br/app/noticia/economia/2015/04/28/internas_economia ,573782/fabrica-da-jeep-em-goiana-da-a-largada-oficial-no-mercado-automotivobrasileiro.shtml. Acessado em 17/07/2015.

EMPRESA BRASILEIRA DE HEMODERIVADOS. Análise Participativa da Realidade

Socioambiental de Goiana. Recife: Hemobrás, cd rom, 2013.

GODOY, José Henrique Artigas de. O Projeto de Suape e suas relações econômicas e socioambientais. $65^{\mathrm{a}}$ Reunião Anual da Sociedade Brasileira para o Progresso da Ciência SBPC, Recife, 2013.

GOIANA. Minuta do Projeto de Lei do Plano Diretor de Desenvolvimento Urbano de Goiana. Dispõe sobre o desenvolvimento urbano do Município de Goiana, institui o Plano Diretor de Desenvolvimento Urbano do Município e dá outras providências, v. 2. 2004. Disponível em: http://adgoiana.pe.gov.br/pdf/Plano_Diretor_Volume_2.pdf. Acessado em $30 / 09 / 2016$.

GUARDA, Adriana. Polo automotivo. Jornal do Commercio, Caderno Especiais, 2015. Disponível em: http://especiais.jconline.ne10.uol.com.br/jeep/. Acessado em 01/10/2016. Bezerra, Bezerra $2018 \quad$ ISSN 0104-5490 
LAYRARGUES, Philippe Pomier. Do Ecodesenvolvimento ao Desenvolvimento Sustentável: Evolução de um Conceito? 1997.

INSTITUTO BRASILEIRO DE GEOGRAFIA E ESTATÍSTICA. Censo demográfico 2010. Rio de Janeiro: IBGE, 2011.

LYRA, T. M.; BEZERRA, A. C. V.; ALBUQUERQUE, M. S. V. Os desafios dos Polos de Desenvolvimento na perspectiva dos atores sociais locais de Goiana, Pernambuco. Physis: Revista de Saúde Coletiva, Rio de Janeiro, 25 [4]: 1117-1139, 2015.

OLIVEIRA, Gilson Batista de. Uma discussão sobre o conceito de desenvolvimento. Revista FAE, Curitiba, v.5, n.2, p.37-48, maio/ago. 2002.

ORGANIZAÇÃO DAS NAÇÕES UNIDAS. Carta das Nações Unidas. 1945. Disponível em: http://unicrio.org.br/img/CartadaONU_VersoInternet.pdf. Acessado em 28/09/2016.

PEREIRA, Anderson. Goiana: Primeira etapa do Northville é concluída. Blog do Anderson Pereira, 2013. Disponível em: http://www.blogdoandersonpereira.com/2013/03/goianaprimeira-etapa-do-northville-e.html. Acessado em 17/07/2015.

Goiana: Fiat não aceita proximidade de fábrica e projeto Cidade Atlântica pode não sair. Blog do Anderson Pereira, 2014. Disponível em: http://www.blogdoandersonpereira.com/2014/01/goiana-fiat-nao-aceita-proximidade-de.html. Acessado em: 07/10/2016.

. Goiana: Lançamento do Loteamento Novo Horizonte foi um sucesso. Blog do Anderson Pereira, 2015a. Disponível em http://www.blogdoandersonpereira.com/2015/03/goiana-lancamento-do-loteamentonovo.html. Acessado em 17/07/2015.

Como contrapartida destinada à saúde: Jeep constrói Pronto Atendimento Especializado em Goiana. Blog do Anderson Pereira, 2015b. Disponível em: http://www.blogdoandersonpereira.com/2015/05/como-contrapartida-destinada-saudejeep.html Acessado em 17/07/2015.

PEREIRA, M. C. de B. Desenvolvimento e meio ambiente: o todo é maior que a soma das partes. Revista Plurais, Goiana, v. 1, n. 2, p. 265-272, 2005.

PÉREZ, M. S.; GONÇALVES, C. U. Desenvolvimento e conflito territorial - primeiras reflexões sobre as comunidades atingidas pelo complexo industrial portuário de Suape PE, Brasil. Revista de Geografia (UFPE), Recife, v. 29, n. 2, p. 166-179, 2012.

PERNAMBUCO. Banco de Dados do Estado de Pernambuco. Perfil Municipal de Goiana. Disponível em: http://www.bde.pe.gov.br/ArquivosPerfilMunicipal/Goiana.pdf. Acessado em 20/10/2016. 
PERNAMBUCO. Federação do Comércio de Bens, Serviços e Turismo do Estado de Pernambuco - FECOMÉRCIO. Perspectivas de Desenvolvimento e Oportunidades do Setor Terciário para o Polo de Desenvolvimento de Goiana - Perfil Socioeconômico do Território, 2015. Volume 1. Recife. Brasil. - Agência Estadual de Planejamento e Pesquisas de Pernambuco CONDEPE/FIDEM. Disponível em http://www.condepefidem.pe.gov.br/web/condepe-fidem. Acessado em 17/06/2014.

SACHS, Ignacy. Desenvolvimento includente, sustentável, sustentado. Rio de Janeiro : Garamond, 2004. 152 p.

SCATOLIN, Fábio Dória. Indicadores de desenvolvimento: um sistema para o Estado do Paraná. Porto Alegre, 1989. Dissertação (Mestrado em Economia) - Universidade Federal do Rio Grande do Sul.

SEN, Amartya. Desenvolvimento como liberdade. São Paulo: Companhia das Letras, 2010. VASCONCELOS, Marco Antonio; GARCIA, Manuel Enriquez. Fundamentos de economia. São Paulo: Saraiva, 1998.

VISTA PLENA. Site institucional, 2016. Disponível em: http://www.vistaplena.com.br/. Acessado em 26/10/2016. 